\title{
Effectiveness and Safety of Switching Originator and Biosimilar Epoetins in Patients with Chronic Kidney Disease in a Large-Scale Italian Cohort Study
}

\author{
Valeria Belleudi ${ }^{1}\left[\right.$ [ Francesco Trotta ${ }^{2} \cdot$ Antonio Addis $^{1} \cdot$ Ylenia Ingrasciotta ${ }^{3} \cdot$ Valentina lentile $^{4} \cdot$ Michele Tari $^{5}$. \\ Rosa Gini ${ }^{6} \cdot$ Maurizio Pastorello ${ }^{7}$. Salvatore Scondotto ${ }^{8} \cdot$ Pasquale Cananzi $^{9} \cdot$ Giuseppe Traversa $^{10} \cdot$ Marina Davoli $^{1}$. \\ Gianluca Trifirò ${ }^{3,4}$ on behalf of the Italian Biosimilar Network (ItaBioNet)
}

Published online: 21 June 2019

(c) The Author(s) 2019

\begin{abstract}
Introduction Real-world data on the comparative effectiveness and safety of switching among different epoetins (including originators and biosimilars) are limited. In light of current debate about interchangeability, prescribers, some patient groups and decision makers are calling for additional post-marketing evidence on the clinical effects of switching between originator and biosimilar epoetins in chronic kidney disease (CKD) patients.

Objective The objective of this study was to evaluate the effectiveness and safety of switching versus non-switching and of switching from originator/biosimilar epoetin alpha (ESA $\alpha$ ) to any other epoetin in CKD patients.

Methods An observational, record-linkage, multi-database, retrospective cohort study was carried out in four Italian geographical areas. All subjects with at least one ESA $\alpha$ dispensing between 1 January 2009 and 31 December 2015 were retrieved. Switching was defined as any transition between originator/biosimilar ESA $\alpha$ to any other epoetin in a series of two consecutive prescriptions up to 2 years. Switchers were matched 1:1 with non-switchers by baseline propensity score and by duration of ESA $\alpha$ treatment. Switchers and non-switchers were followed up from switching date to a maximum of 1 year. Lack of effectiveness and safety of switching versus non-switching were evaluated through Cox regression models (hazard ratio [HR], 95\% confidence interval [CI]). A direct comparison between the two switcher categories (switchers from originator/biosimilar ESA $\alpha$ to any other epoetin) was also performed.

Results Overall, 14,400 incident users of ESA $\alpha$ for anaemia due to CKD (61.4\% originator, $38.6 \%$ biosimilar) were available for analysis. During the follow-up, we found no differences on effectiveness (HR 1.02, 95\% CI 0.79-1.31 originators; HR 1.16, 95\% CI $0.75-1.79$ biosimilars) and safety outcomes (HR 1.08, 95\% CI 0.77-1.50 originators; HR 1.20, $95 \%$ CI 0.66-2.21 biosimilars) between switchers and non-switchers of ESA $\alpha$. Cumulative probabilities of recording an adverse event, either in terms of lack of effectiveness or safety issue, were the same for two switching categories

Conclusions In this large-scale Italian observational multi-database study, switching versus non-switching as well as switching from biosimilar/originator ESA $\alpha$ to any other epoetin in CKD patients is not associated with any effectiveness and safety outcomes.
\end{abstract}

Valeria Belleudi and Francesco Trotta contributed equally to this article.

The members of the Italian Biosimilar Network (ItaBioNet) are listed in acknowledgements.

Electronic supplementary material The online version of this article (https://doi.org/10.1007/s40264-019-00845-y) contains supplementary material, which is available to authorized users.

Valeria Belleudi

v.belleudi@deplazio.it

Extended author information available on the last page of the article

\section{Key Points}

To improve the acceptance of biosimilars in the medical community, we need data from real-world settings on the effectiveness and safety of switching among biosimilars/ originators.

Switching from epoetin alpha to any epoetin (biosimilar/ originator) in chronic kidney disease patients appears to be effective and safe both when compared with nonswitchers or among switchers. 


\section{Introduction}

The erythropoiesis-stimulating agents (ESAs) play a major role in the management of anaemia in several therapeutic settings. In particular, benefits with these drugs for the treatment of anaemia that is induced by chemotherapy or associated to chronic kidney disease (CKD) are well-documented [1-6]. Since 2007 in Europe, the biosimilar version of epoetin alpha (ESA $\alpha)$ has been available, following approval by the European Medicines Agency (EMA) on the basis of absence of clinically meaningful differences in safety, efficacy and immunogenicity as compared to the reference product [7].

In general, the uptake of biosimilars is heterogeneous across countries and therapeutic areas, highlighting differences in the confidence of clinicians in prescribing these biologics [8]. In fact, the acceptance of biosimilars in the medical community continues to be limited in some countries and therapeutic areas even though they represent a great opportunity for the sustainability of the national health services (NHSs) [9-14]. Biosimilar consumption in Italy in 2017 represented $51 \%$ of the entire class of ESAs, which was strongly influenced by the implementation of different regional healthcare policies [15]. Recent population-based studies documented that almost $20 \%$ of patients switched among different ESAs during the first year of treatment, even if this was more frequently toward originators rather than biosimilars [16-18].

A recent systematic review based on randomised clinical trial (RCT) data evaluating the evidence on switching among different ESAs highlighted an overall therapeutic equivalence in those switching to any ESA [19]. In addition, spontaneous reporting systems as well as post-marketing RCTs did not detect any drug safety signal concerning switching from one epoetin to another [20]. While post-marketing evidence has been satisfactorily cumulated about the comparable benefit/risk profile of CKD patients starting a firstever treatment with either biosimilar or originator ESAs in routine care [21-25], the effect of switching among different ESAs on 'hard' clinical outcomes (i.e. dyscrasias, major cardiovascular events [MACE], etc.) in a real-world setting remains not fully investigated [26].

For this reason, this large-scale observational study was aimed at evaluating the comparative effectiveness and safety of switching from ESA $\alpha$ (both originator or biosimilars) to other ESAs versus non-switchers in CKD patients. The secondary objective of this study was to assess a direct comparison among switchers, i.e. those switching from the ESA $\alpha$ originator versus those switching from biosimilars.

\section{Methods}

\subsection{Study Design and Data Source}

We conducted an observational, record-linkage, multi-database, retrospective cohort study using healthcare databases from four Italian areas, located in the central and southern part of the country, covering a total population of more than 12 million inhabitants.

Fully anonymised data were retrieved from administrative databases of the catchment area of each participating centre (Lazio and Tuscany Regions, and Caserta and Palermo Local Health Units). In particular, individual-level information was retrieved on dispensed drugs reimbursed by the NHS, hospital discharges, emergency department (ED) visits, exemptions from co-payment to healthcare services, and prescriptions of laboratory tests. The Anatomical Therapeutic Chemical (ATC) classification system was used to code drugs, while the International Classification of Disease, Clinical Modification, Ninth Revision (ICD9-CM) was used to code diseases in relation to healthcare services payment exemption, the diagnoses at hospital discharges and the reasons for ED visits.

\subsection{Study Population}

All subjects with at least one ESA $\alpha$ (originator; Eprex ${ }^{\circledR}$, Janssen-Cilag SpA, Milan, Italy) or biosimilar (Abseamed ${ }^{\circledR}$, Medice Arzneimittel Pütter GmbH Co. KG, Iserlohn, Germany; Binocrit ${ }^{\circledR}$, Sandoz GmbH, Kundl, Austria; and Retacrit $^{\circledR}$, Pfizer Europe MA EEIG, Bruxelles, Belgio) dispensing between 1 January 2009 and 31 December 2015 were considered. The date of the first dispensing was identified as the baseline date. In order to capture the clinical history through the health information system, only patients with at least 1 year of health assistance prior to the baseline date were selected. Furthermore, the study cohort was restricted to subjects without any ESA prescriptions in the 6 months before baseline (new users) and who were treated because they had a recorded diagnosis of CKD. Finally, patients who did not receive a second ESA dispensing within 120 days were discarded; this cut-off limit was chosen considering the mean duration of the therapy regimen recorded by the Therapeutic Plan Register [23].

\subsection{Exposure}

For each subject, all consecutive ESA prescriptions up to the 2 years following the baseline date were retrieved. Two prescriptions were defined as consecutive if the time between them was $\leq 120$ days. 
ESAs were grouped into four mutually exclusive categories: (1) ESA $\alpha$ originator; (2) ESA $\alpha$ biosimilar; (3) short-acting epoetins (Neorecormon ${ }^{\circledR}$, Roche Registration GmbH, Grenzach-Wyhlen, Germany; Eporatio ${ }^{\circledR}$, Ratiopharm GmbH, Ulm, Germany); and (4) long-acting epoetins (Aranesp ${ }^{\circledR}$, Amgen Europe B.V., Breda, Netherlands; Nespo ${ }^{\circledR}$, Dompé Biotec S.p.A., Milan, Italy; Mircera ${ }^{\circledR}$, Roche Registration GmbH, Welwyn Garden City, UK).

Considering all consecutive ESA prescriptions, switching from ESA $\alpha$ (whether biosimilar or not) was defined as any transition to another ESA category, while the nonswitcher cohort consisted of subjects with at least two consecutive prescriptions and without any ESA transition.

\subsection{Covariates}

Demographic and clinical characteristics of the cohort at the baseline date were retrieved. More specifically, age, sex, geographical area, factors related to anaemia (blood transfusion, hospitalisation due to anaemia, iron supplementation), indication for ESA use (dialysed/non-dialysed CKD) and co-morbidities/concomitant medications (cancer, diabetes mellitus, hypertension, arrhythmia, heart failure, cerebrovascular events, thrombosis, respiratory disease, hyperparathyroidism, hyperkalaemia, hyperphosphataemia, folic acid, vitamins, non-steroidal anti-inflammatory drugs [NSAIDs]) were retrieved (see Electronic Supplementary Material).

\subsection{Matching}

Within each ESA $\alpha$ users group (i.e. initiators of originator or biosimilar) a matched cohort was created to compare the risk of study outcomes in switchers versus non-switchers. For this purpose, we calculated a propensity score based on baseline characteristics. For the switcher group, the duration of ESA $\alpha$ treatment was measured considering the time difference between the baseline date and the date of switching (index date [ID]). Switchers were matched 1:1 with nonswitchers by propensity score (caliper $=0.10$ ), geographical area and duration of ESA $\alpha$ treatment ( \pm 30 days) (Fig. 1).

Only subjects without lack of effectiveness and without safety events during the 90 days prior to switching were considered.

\subsection{Follow-Up}

All patients were followed from the ID until one of the following events, whichever came first: treatment discontinuation (i.e. 120 days lag time following the last dispensing), transferring out from the catchment area, study outcome, switch, 1 year or end of the study (31 December 2016).

\subsection{Outcomes}

The outcomes of interest concerned both the effectiveness and safety of ESAs. Blood transfusions or anaemia

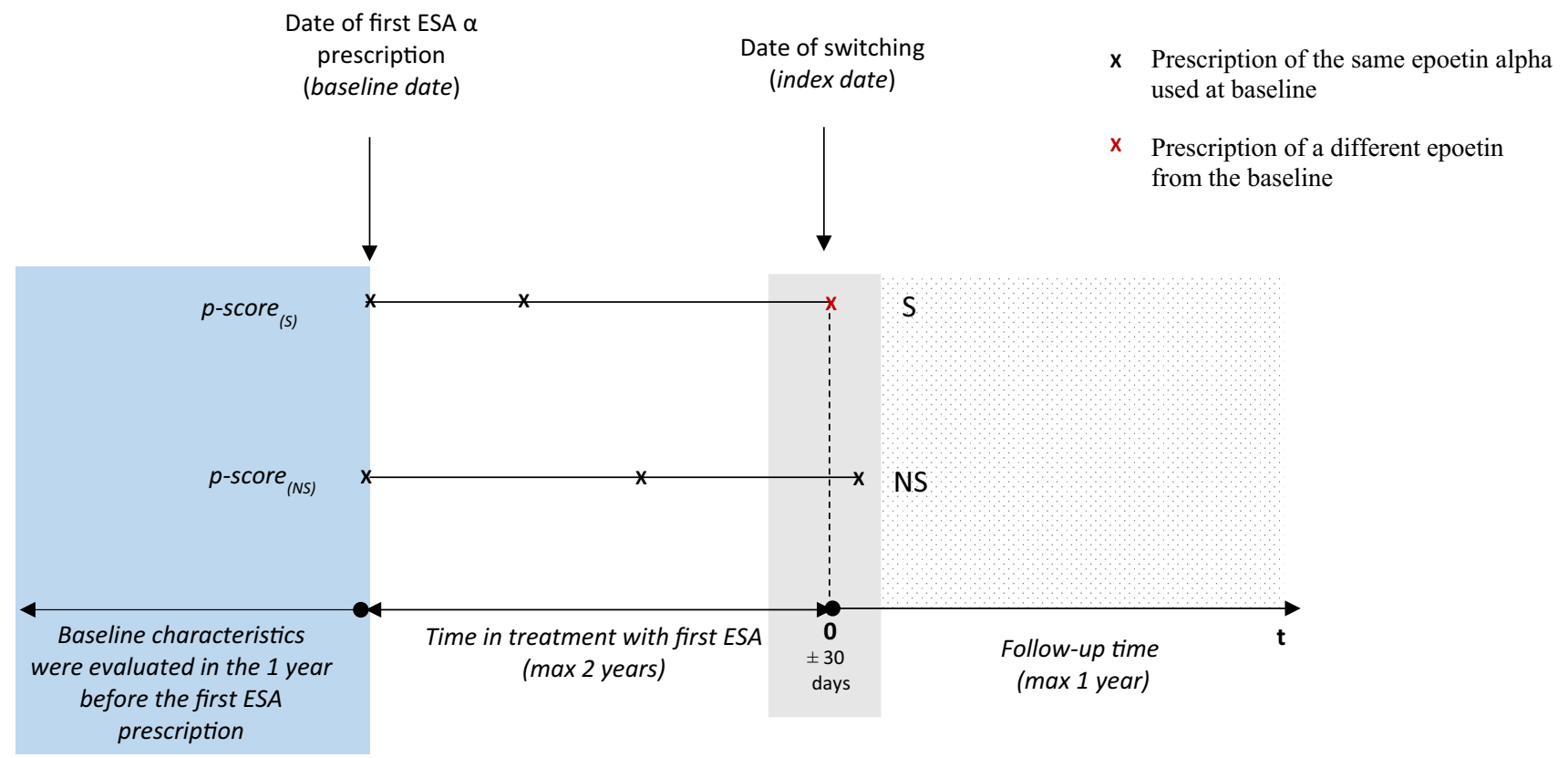

Fig. 1 Study design. Switchers (S) were matched with non-switchers (NS) 1:1 by propensity score (caliper=0.10) and time in treatment with first epoetin alpha $(\mathrm{ESA} \alpha)( \pm 30$ days). ESA erythropoiesis-stimulating agent, max maximum 
were considered as proxies for lack of effectiveness, while MACE, dyscrasias or hypersensitivity reactions were evaluated as proxies for safety (for more details see the Electronic Supplementary Material).

\subsection{Statistical Analysis}

The comparison of patients' characteristics between switchers and non-switchers, before and after matching was performed within the two groups of ESA $\alpha$ users (i.e. originator or biosimilars). To assess the effectiveness and safety of switching, the adjusted hazard ratios (HRs) and related confidence intervals (CIs) were estimated by fitting Cox models within both ESA $\alpha$ originator and biosimilar initiators, using non-switchers as a reference group.

\subsection{Sensitivity and Subgroup Analyses}

Cox models were also fitted within by different switching subgroups and their matched non-switchers depending on the second ESA received within each initiator group:

- from originator of ESA $\alpha$ to (1) biosimilars; (2) shortacting patented epoetins; or (3) long-acting patented epoetins; and

- from biosimilars of ESA $\alpha$ to (4) originator; (5) shortacting patented epoetins; and (6) long-acting patented epoetins.

In order to analyse the robustness of our results, the following sensitivity and subgroup analyses were carried out:

- Analysis of the subgroup of subjects with a more conservative matching definition, i.e. reducing the duration of ESA $\alpha$ treatment from \pm 30 days to \pm 15 days, to increase the comparability between groups.

- Restriction of the risk window for the switching occurrence, i.e. from 2 years to 180 days following the initiation of the first ESA $\alpha$ treatment. This would mitigate the time-dependent bias due to baseline adjustment.

- Application of different definitions of follow-up, i.e. considering a fixed follow-up of 1 year and two different windows of follow-up (90 and 180 days).

Finally, a comparison between the two switcher cohorts (i.e. switchers from originator to any other ESAs or from biosimilars to any other ESAs) was performed in terms of lack of effectiveness and safety. In this analysis, only switchers were selected and the cumulative probabilities of observing an effectiveness or a safety event within each switching cohort for each category were estimated by Cox model, adjusting for baseline characteristics.

\section{Results}

During the study period, 52,178 ESA $\alpha$ users were identified; $86.3 \%(45,012)$ of these were new users with at least 1 year of health assistance history (Fig. 2). There were 18,612 patients using ESA $\alpha$ for anaemia due to CKD, despite $22.6 \%$ of them showing a sporadic use (i.e. only one ESA dispensing in the following 4 months).

Considering the overall study population $(n=14,400)$, $8843(61.4 \%)$ subjects started the therapy with an ESA $\alpha$ originator while $5557(38.6 \%)$ received a biosimilar. In the two groups of ESA $\alpha$ initiators, the percentages of switching within 2 years from the first epoetin prescription (originator or biosimilars) were $21.1 \%$ and $11.5 \%$, respectively.

Switchers who showed no effectiveness and safety events during the 90 days prior to the switching date were excluded $(10.2 \%)$ as were switchers for whom there were no matching non-switchers $(6.6 \%)$.

In the ESA $\alpha$ originator group, the most frequent switch occurred to long-acting epoetins (58.5\%), while only $14.2 \%$ of the patients experienced a switch to biosimilars; instead, among biosimilar initiators the most frequent switch occurred towards ESA $\alpha$ originators $(43.1 \%)$.

Characteristics of originator/biosimilar switchers and non-switchers, before and after the matching, are shown in Table 1. Overall, younger patients with a greater severity of $\mathrm{CKD}$ and with more co-morbidities or a greater number of hospitalizations prior to the ESA $\alpha$ therapy start were more frequent among switchers. After the matching, the baseline characteristics of patients were well-balanced. Furthermore, for both initiator groups, more than 50\% of the switching occurred during the first 6 months of ESA therapy (Fig. 3).

Overall, lack of effectiveness and safety outcomes occurred in $7.7 \%$ and $4.5 \%$ of the originator ESA $\alpha$ initiators, respectively; while in the biosimilar group these percentages were $7.8 \%$ and $4.0 \%$.

The adjusted HRs for the main analysis, the subgroup as well as the sensitivity analyses for all considered outcomes are presented separately for the two ESA $\alpha$ initiators groups in Fig. $4 a-d$. In the originator initiator group (Fig. 4a), no difference in the risk of lack of effectiveness between switchers and non-switchers was found (HR 1.02, 95\% CI $0.79-1.31$ ). In the biosimilar initiator group (Fig. 4b), a slight, non-statistically significant risk increase in terms of lack of effectiveness was observed for switchers versus nonswitchers (HR 1.16, 95\% CI 0.75-1.79). When considering the safety outcome, a non-statistically significant risk for switchers was observed in both originator (HR 1.08, 95\% CI $0.77-1.50$ ) or biosimilar (HR 1.20, 95\% CI 0.66-2.21) ESA $\alpha$ initiators (Fig. 4c, d).

Results showed in the main analysis on lack of effectiveness risk between switchers and non-switchers for originator 
Fig. 2 Study population. ESA erythropoiesis-stimulating agent, ESA $\alpha$ epoetin alpha

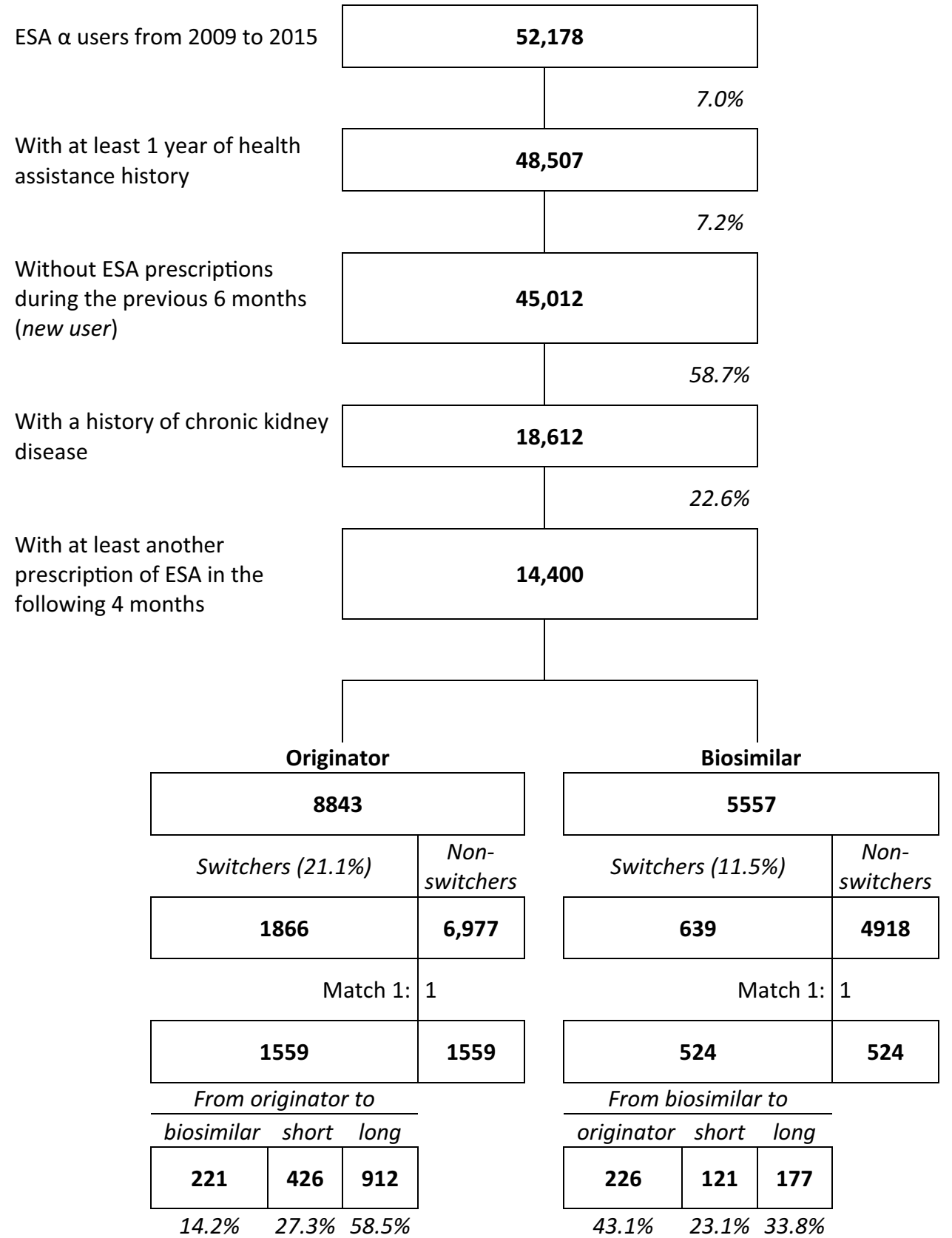

and biosimilar initiator groups were consistent across different switching subgroups. In particular, in the subgroup of switchers from ESA $\alpha$ originator to biosimilar, the risk was 0.86 (95\% CI 0.44-1.66). Results also remained unchanged in the sensitivity analyses, i.e. when using a more conservative matching definition (subgroup analysis 2: HR 1.02, 95\% CI 0.76-1.37 for originator initiator group; HR 1.02, 95\% CI $0.60-1.73$ for biosimilar initiator group), restricting the period for the switching occurrence to 180 days (subgroup analysis 2: HR $1.05,95 \%$ CI $0.76-1.45$ for originator initiator group; HR 1.08, 95\% CI 0.65-1.78 for biosimilar initiator group) or considering different definitions of follow-up.
The main analysis on safety risk was substantially confirmed from subgroup and sensitivity analyses. A slight increase in the subgroup of switchers from originator to biosimilar (HR $1.18,95 \%$ CI $0.49-2.83$ ) and from biosimilar to originator (HR 1.52, 95\% CI 0.54-3.90) was found without reaching statistical significance.

As shown in Fig. 5a, b, cumulative probabilities of occurrence of any lack of effectiveness or safety outcomes were found to be highly similar for both switching groups; the estimated HRs (switching from ESA $\alpha$ biosimilars vs. switching from ESA $\alpha$ originator) were equal to 1.03 (95\% CI 0.69-1.53) and 0.92 (95\% CI 0.54-1.59), respectively. 


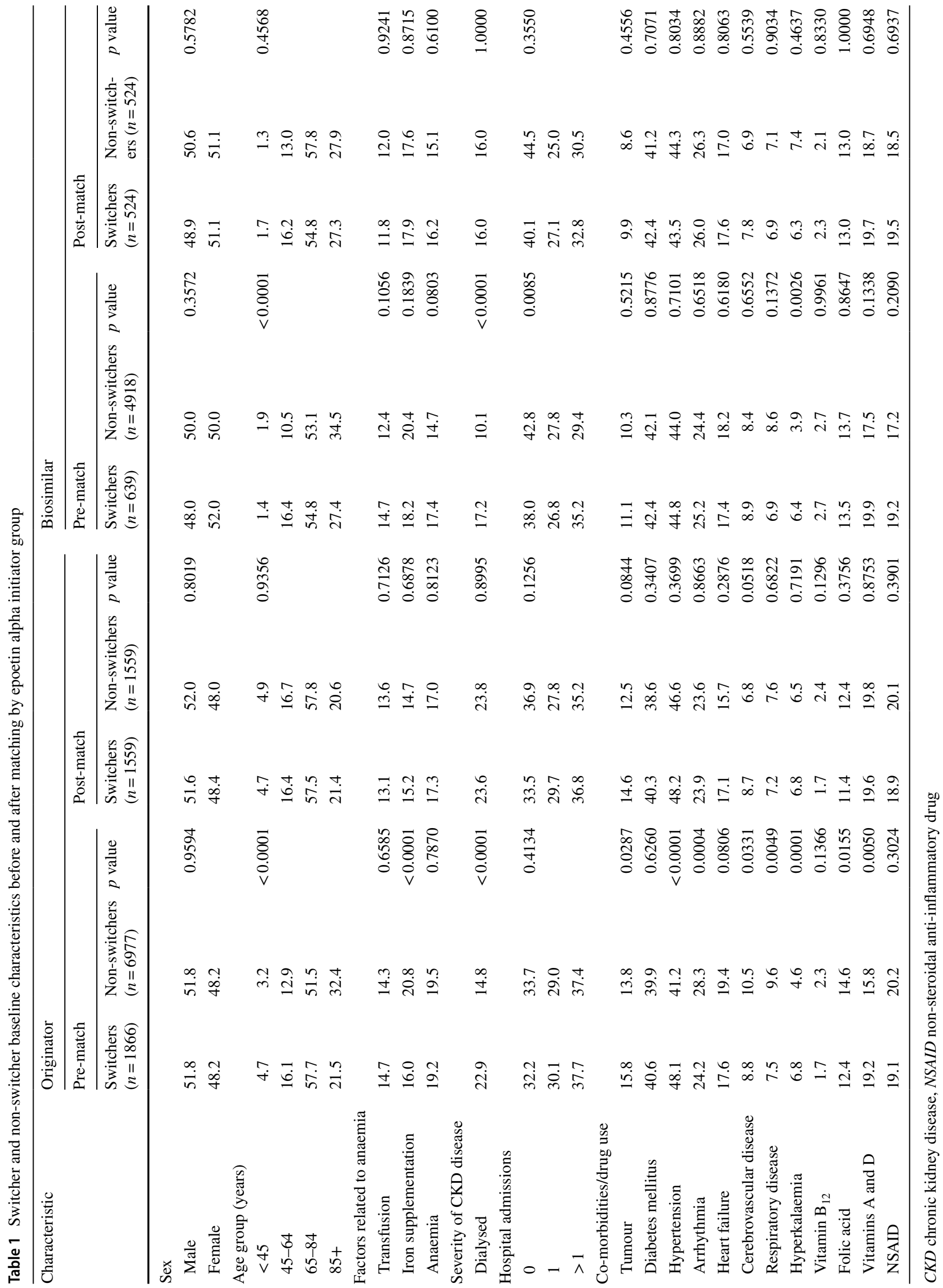




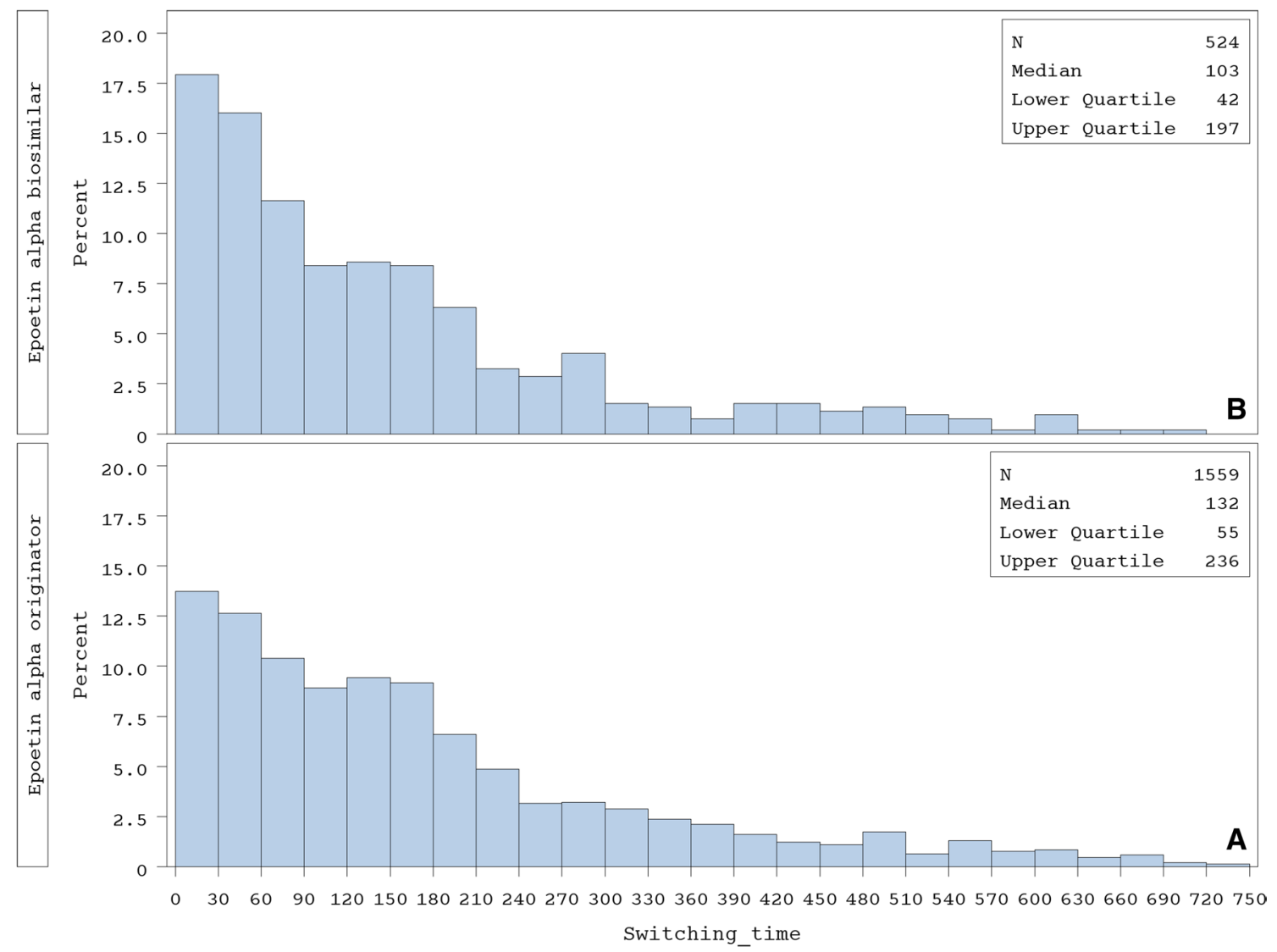

Fig. 3 Switching time in originator (a) and biosimilar (b) initiator groups

\section{Discussion}

This study provided real-world data on switching from ESA $\alpha$ originator or biosimilar to any other ESA in a large cohort of Italian CKD patients. The results suggest that originator/biosimilar ESA $\alpha$ initiators who switched to any other ESA during the first 2 years of treatment did not experience an increased risk of lack of effectiveness or safety outcomes in the year following switching when compared with non-switchers. These findings were consistent among subgroups and were confirmed by sensitivity analyses. Furthermore, switchers from ESA $\alpha$ biosimilar treatment did not experience an increased risk of lack of effectiveness or safety outcomes in the year following switching when compared with switchers from ESA $\alpha$ originator.

\subsection{Comparison with Other Available Evidence in the Field}

To our knowledge, this is the first study aimed at evaluating the impact of switching in a large cohort of ESA $\alpha$ users with CKD from the real-world setting using hard clinical outcomes.

To date, the available evidence has been derived from a few studies investigating the efficacy of ESA switching in terms of maintenance of haemoglobin levels in the nephrology setting [27-31]; moreover, all of these studies enrolled a small sample population (from 125 up to almost 800 subjects) and mainly referred to haemodialysis settings. In this context, it is of utmost importance to underline that none of the studies conducted performed a direct comparison among different switching groups. In particular, three of these studies showed conflicting results in terms of the doses of ESA $\alpha$ that were required to control anaemia in CKD patients switching from originator to biosimilar [29-31].

Several reviews also contributed to ascertaining the available evidence on the consequences of switching from originators to related biosimilars, although they were not focused exclusively on ESAs [20, 22, 32]. In particular, these three studies did not find any differences in terms of immunogenicity, safety or efficacy between those continuing therapy with originators or those switching to biosimilars, 

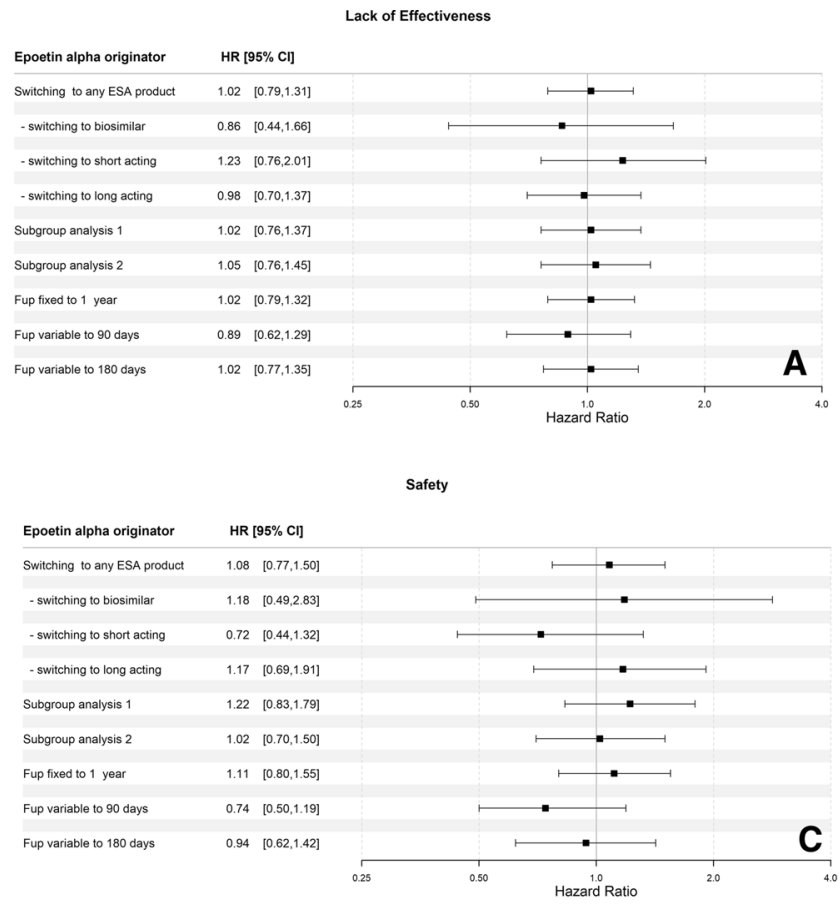

Fig. 4 Adjusted hazard ratios (HRs) and sensitivity analyses for all considered outcomes in epoetin alpha initiator groups. a HR lack of effectiveness outcomes for switchers versus non-switchers in the originator initiators group; b HR lack of effectiveness outcomes for switchers versus non-switchers in the biosimilar initiators group; c HR safety outcomes for switchers versus non-switchers in the originator initiators group; and d HR safety outcomes for switchers ver-

thus indicating that concerns related to switching have been so far unsupported.

\subsection{Implication for Policy}

Relevance of all issues related to the switch phenomenon led the national and international regulatory authorities to define guidance summarising the requirements necessary to establish the safety and efficacy of all biologic medicines that could be switched [13, 14, 33]. In the EU context, the EMA declared that in case of naïve patients there is no need for additional evaluation by the member states for starting with a biosimilar, including cases where extrapolation of the indication was applied. Even though the EMA declared that it "does not regulate interchangeability, switching and substitution of a reference medicine by its biosimilar" [34], several authors and European national drugs agencies stated that switching between biological drugs is safe [35]. In particular, in Italy, the national regulatory body for medicines took the position in favour of biosimilar and reference product interchangeability as part of the remit by the prescribers [14].
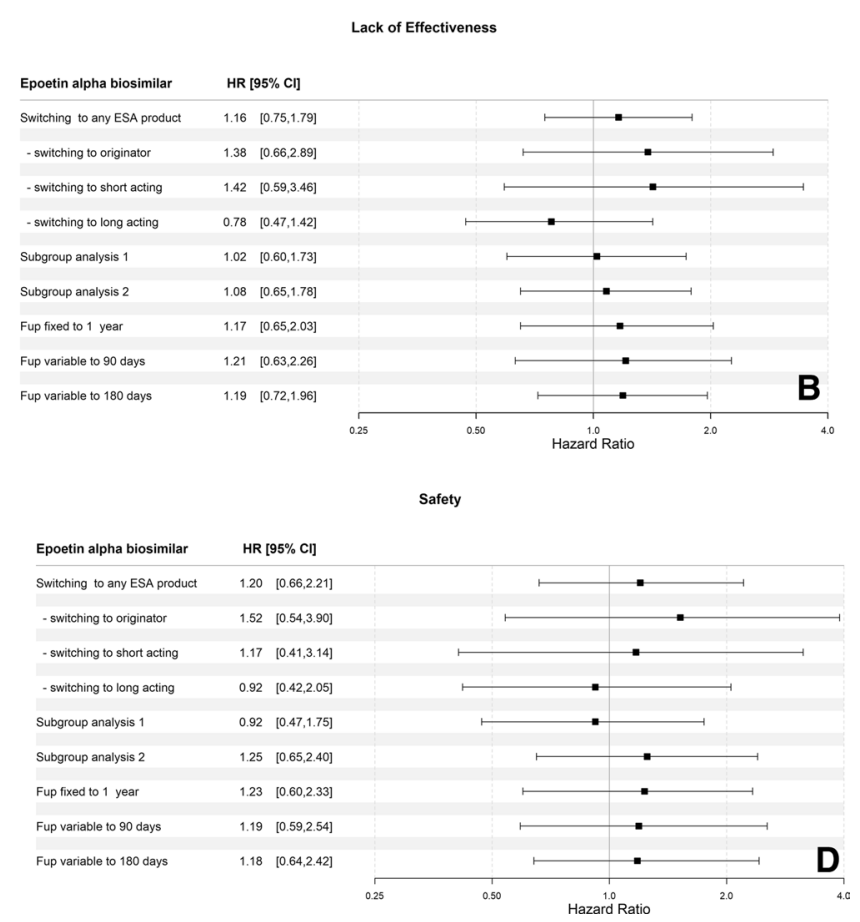

sus non-switchers in the biosimilar initiators group. Subgroup analysis 1: subject with a more conservative definition matching, i.e. time in treatment with first epoetin alpha \pm 15 days. Subgroup analysis 2 : subjects switching within 180 days from beginning of first epoetin alpha treatment. $C I$ confidence interval, ESA erythropoiesis-stimulating agent, Fup follow-up

The switching phenomenon is not only related to the potential cost saving offered by biosimilars, but is something to be considered as a medical issue, especially as it may also occur among different originators. In fact, all new drugs coming onto the market with an existing therapeutic indication are potential switches for current patients treated chronically. In particular, in our study, as well as in previously published analyses [16-18], the majority of switching took place among originators.

Thus, as suggested by several authors [36, 37], switching studies will help to uncover any residual uncertainty between the actions of two drugs, and, in the case of interchangeability, that uncertainty needs to be as minimal as possible because of safety concerns related to immunogenicity.

\subsection{Strengths and Weaknesses of the Study}

This is an observational study based on health information systems, without direct access to clinical records. The main limitations of our study are the lack of important information on disease severity such haemoglobin and iron levels. 

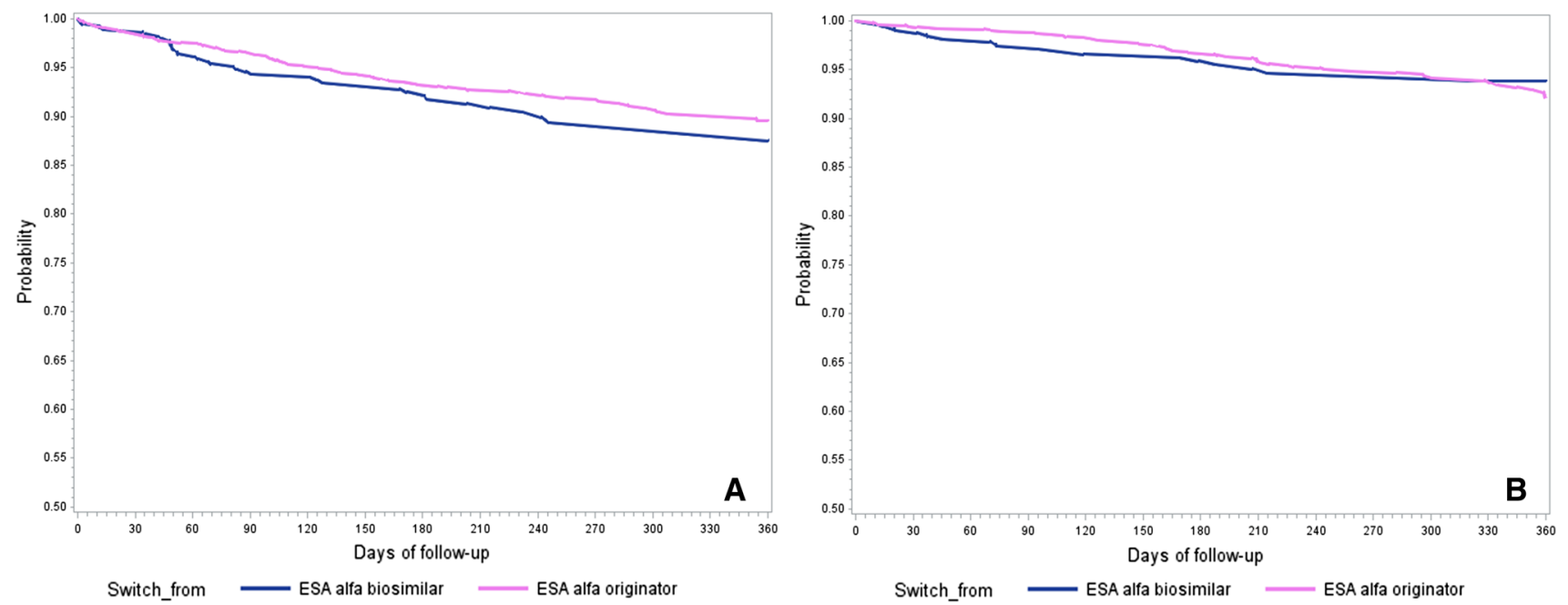

Fig. 5 Cumulative probabilities of recording a lack of effectiveness (a) or safety event (b) between epoetin switchers. ESA $\alpha$ epoetin alpha

However, some information on patient characteristics were identified through multiple database linkages, ensuring proper control of confounding for measurable characteristics.

Another possible concern was the choice of study design. We decided to use a 2-year period to define switcher and non-switcher groups and then we matched them by propensity score and duration of previous drug use before the switch. Thus, the reference group included patients that did not switch for at least 2 years. Since switching could have been caused by clinical issues, we might have selected less severe patients in the non-switcher group. This potential selection bias could result in a slight increase of risk. We hypothesise that replicating the study considering non-switcher/switcher times instead of the non-switchers/ switcher groups would mean the estimated risk for switchers would be lower than for non-switchers. However, we chose to adopt a more comprehensible approach with a more conservative reference group and performed an analytical approach to balance the study groups taking into account baseline factors. Furthermore, several pre-specified subgroup analyses were also performed in order to evaluate consistency of findings which were in line with those obtained from the main analysis.

Moreover, the sample size for the biosimilar initiator group was lower than for the originator group and this led to wider CIs and thus a less precise estimation of the HRs. In this context, a product-specific analysis could bring more information, but it would require a larger cohort of patients exposed to all different kinds of ESAs. In fact, our analysis does not allow consideration of differences between specific products within the same group (i.e. Retacrit $^{\circledR}$ vs. Abseamed ${ }^{\circledR} /$ Binocrit $\left.^{\circledR}\right)$. Another limitation of our study was that we analysed only a single switch from originator to biosimilar. Suggestions have been made that there may be an increased safety risk if patients are switched back and forth multiple times between a reference biologic and one or more biosimilars.

\section{Conclusions}

This large-scale observational study suggests that switching from ESA $\alpha$ to other ESAs in CKD patients is effective and safe when compared with non-switching, both within biosimilar and within originator initiators, and that switching from originator is effective and safe when compared with switching from a biosimilar in a real-world setting. These results may be very useful to support clinical decisions related to switching drug therapies and promote better health policies to improve the uptake of biosimilars in the population.

Acknowledgements The authors wish to thank Serena Perna, Alessandro Cesare Rosa and Francesca Romana Poggi of the Department of Epidemiology of Lazio Regional Health Service for comments and suggestions on the final version of the manuscript. The following are members of the Italian Biosimilar Network (ItaBioNet): Gianluca Trifirò, Achille P. Caputi, Ylenia Ingrasciotta, Francesco Giorgianni, Ilaria Marcianò, Valentina Ientile, Alessandro Chinellato, Jenny Bolcato, Roberta Pirolo, Rosa Gini, Giuseppe Roberto, Armando A. Genazzani, Michele Tari, Maurizio Pastorello, Ilaria Uomo, Salvatore Scondotto, Sebastiano W. Pollina Addario, Pasquale Cananzi, Roberto Da Cas, Giuseppe Traversa, Mariangela Rossi, Marina Davoli, Francesco Trotta, Valeria Belleudi, Antonio Addis.

\section{Compliance with Ethical Standards}

Funding The study was conducted in the context of the "Assessment of Short and Long Term Risk-Benefit Profile of Biologics Through Healthcare Database Network in Italy" project coordinated by the University of Messina, funded by the Italian Ministry of Health. Only pub- 
lic researchers of the local and regional health authorities or academia were involved in the study.

Conflict of interest Rosa Gini discloses a personal interest in sustainability of universal healthcare systems. Valeria Belleudi, Francesco Trotta, Antonio Addis, Ylenia Ingrasciotta, Valentina Ientile, Michele Tari, Maurizio Pastorello, Salvatore Scondotto, Pasquale Cananzi, Giuseppe Traversa, Marina Davoli and Gianluca Trifirò declare no conflict of interest.

Author contributions GT, FT, VB, AA, RG, MD and GTra conceived the study. FT, VB, GT, AA and RG designed the study. FT, RG and VB analysed the data. FT and VB wrote the manuscript. MT, MP, SS, PC and RG provided the data and were responsible for their quality. All authors saw, commented and approved the final version of the paper. GT and MD are the guarantors.

Ethical standards Ethical approval was achieved from regional and local health authorities.

Open Access This article is distributed under the terms of the Creative Commons Attribution-NonCommercial 4.0 International License (http://creativecommons.org/licenses/by-nc/4.0/), which permits any noncommercial use, distribution, and reproduction in any medium, provided you give appropriate credit to the original author(s) and the source, provide a link to the Creative Commons license, and indicate if changes were made.

\section{References}

1. Associazione Italiana di Oncologia Medica. Linee Guida Gestione della tossicità ematopoietica in oncologia Milan; 2017. http://media.aiom.it/userfiles/files/doc/LG/2017_LGAIOM_ Toss_ematopoietica.pdf. Accessed 25 Jan 2018.

2. Kidney Disease: Improving Global Outcomes (KDIGO) Anemia WorkGroup. KDIGO clinical practice guideline for anemia in chronic kidney disease. Kidney Int Suppl. 2012;2(4). https:// kdigo.org/wp-content/uploads/2016/10/KDIGO-2012-Anemi a-Guideline-English.pdf. Accessed 25 Jan 2018.

3. Sistema Nazionale Linee Guida -Istituto Superiore di Sanità, Società Italiana di Nefrologia, Ministero della Salute. Linea Guida "Identificazione, prevenzione e gestione della Malattia Renale Cronica nell'adulto". 2015. https://www.fadoi.org/ wp-content/uploads/2017/05/lineeguida-Malattia-renale-croni ca-adulto.pdf. Accessed 25 Jan 2018.

4. Aapro MS, Link H. September 2007 update on EORTC guidelines and anemia management with erythropoiesis-stimulating agents. Oncologist. 2008;13(Suppl 3):33-6.

5. Rizzo JD, Brouwers M, Hurley P, Seidenfeld J, Arcasoy MO, Spivak JL, et al. American Society of Clinical Oncology, American Society of Hematology. American Society of Clinical Oncology/ American Society of Hematology clinical practice guideline update on the use of epoetin and darbepoetin in adult patients with cancer. J Clin Oncol. 2010;28(33):4996-5010.

6. National Comprehensive Cancer Network (NCCN). NCCN ${ }^{\circledR}$ guidelines. Cancer- and chemotherapy-induced anemia (version 2.2018). 2017. http://oncolife.com.ua/doc/nccn/Cancer-and_ Chemotherapy-Induced_Anemia.pdf. Accessed 25 Jan 2018.

7. Biosimilar development and approval in the EU. European public assessment reports. London: The European Medicines Agency. https://www.ema.europa.eu/en/human-regulatory/overview/biosi milar-medicines-overview\#biosimilar-development-and-approvalin-the-eu-section. Accessed 25 May 2019.

8. IMS Institute for Healthcare Informatics. The impact of biosimilar competition in Europe. QuintilesIMS; 2017. https://www.medic inesforeurope.com/wp-content/uploads/2017/05/IMS-Biosimilar -2017_V9.pdf. Accessed 15 Apr 2017.

9. Dylst P, Vulto A, Simoens S. Barriers to the uptake of biosimilars and possible solutions: a Belgian case study. Pharmacoeconomics. 2014;32(7):681-91.

10. Rompas S, Goss T, Amanuel S, Coutinho V, Lai Z, Antonini P, et al. Demonstrating value for biosimilars: a conceptual framework. Am Health Drug Benefits. 2015;8(3):129-39.

11. Lyman GH, Zon R, Harvey RD, Schilsky RL. Rationale, opportunities, and reality of biosimilar medications. N Engl J Med. 2018;378(21):2036-44.

12. Trifirò G, Marcianò I, Ingrasciotta Y. Interchangeability of biosimilar and biological reference product: updated regulatory positions and pre- and post-marketing evidence. Expert Opin Biol Ther. 2018;18(3):309-15.

13. European Medicines Agency. Biosimilars in the EU: information guide for healthcare professionals. 2017. http://www.ema.europ a.eu/docs/en_GB/document_library/Leaflet/2017/05/WC500 226648.pdf. Accessed 15 Apr 2017.

14. Agenzia Italiana del Farmaco (AIFA). Secondo Position Paper AIFA sui Farmaci Biosimilari. http://www.agenziafarmaco.gov. it/sites/default/files/2_Position-Paper-AIFA-Farmaci-Biosimilar i.pdf. Accessed 15 Apr 2017.

15. Osservatorio Nazionale sull'impiego dei Medicinali. L'uso dei farmaci in Italia. Rapporto Nazionale 2017. Roma: Agenzia Italiana del Farmaco; 2018. http://www.aifa.gov.it/sites/default/files/ Rapporto_OsMed_2017_AIFA.pdf. Accessed 18 Jun 2018.

16. Ingrasciotta Y, Giorgianni F, Marcianò I, Bolcato J, Pirolo R, Chinellato A, et al. Comparative effectiveness of biosimilar, reference product and other erythropoiesis-stimulating agents (ESAs) still covered by patent in chronic kidney disease and cancer patients: an Italian population-based study. PLoS One. 2016;11(5):e0155805.

17. Loiacono C, Sgroi C, Coppolino S, Cannata A, Ferrara R, Arcoraci $\mathrm{V}$, et al. How much are biosimilars used in southern Italy? A retrospective analysis of epoetin utilization in the local health unit of Messina in the years 2010-2011. BioDrugs. 2012;26(2):113-20.

18. D'Amore C, Da Cas R, Rossi M, Traversa G. Switching between epoetins: a practice in support of biosimilar use. BioDrugs. 2016;30(1):27-32.

19. Cohen HP, Blauvelt A, Rifkin RM, Danese S, Gokhale SB, Woollett G. Switching reference medicines to biosimilars: a systematic literature review of clinical outcomes. Drugs. 2018;78(4):463-78.

20. Ebbers HC, Muenzberg M, Schellekens H. The safety of switching between therapeutic proteins. Expert Opin Biol Ther. 2012;12(11):1473-85.

21. Palmer SC, Saglimbene V, Mavridis D, Salanti G, Craig JC, Tonelli M, et al. Erythropoiesis-stimulating agents for anaemia in adults with chronic kidney disease: a network meta-analysis. Cochrane Database Syst Rev. 2014;12:CD010590.

22. Amato L, Addis A, Saulle R, Trotta F, Mitrova Z, Davoli M. Comparative efficacy and safety in ESA biosimilars vs. originators in adults with chronic kidney disease: a systematic review and meta-analysis. J Nephrol. 2018;31(3):321-32.

23. Trotta F, Belleudi V, Fusco D, Amato L, Mecozzi A, Mayer F, et al. Comparative effectiveness and safety of erythropoiesis-stimulating agents (biosimilars vs originators) in clinical practice: a population-based cohort study in Italy. BMJ Open. 2017;7(3):e011637.

24. Stoppa G, D'Amore C, Conforti A, Traversa G, Venegoni M, Taglialatela $\mathrm{M}$, et al. Comparative safety of originator and 
biosimilar epoetin alfa drugs: an observational prospective multicenter study. BioDrugs. 2018;32(4):367-75.

25. Motola D, Vaccheri A, Roncadori A, Donati M, Bonaldo G, Covezzoli A, et al. Comparative risk/benefit profile of biosimilar and originator erythropoiesis-stimulating agents (ESAs): data from an Italian observational study in nephrology. Eur J Clin Pharmacol. 2018;74(6):805-10.

26. Ingrasciotta Y, Giorgianni F, Bolcato J, Chinellato A, Pirolo R, Tari DU, et al. How much are biosimilars used in clinical practice? A retrospective Italian population-based study of erythropoiesis-stimulating agents in the years 2009-2013. BioDrugs. 2015;29(4):275-84.

27. Hörl WH, Locatelli F, Haag-Weber M, Ode M, Roth K, EpoPASS Study Group. Prospective multicenter study of HX575 (biosimilar epoetin- $\alpha$ ) in patients with chronic kidney disease applying a target hemoglobin of 10-12 g/dl. Clin Nephrol. 2012;78(1):24-32.

28. Donck J, Gonzalez-Tabares L, Chanliau J, Martin H, Stamatelou K, Manamley N, et al. Preservation of anemia control and weekly ESA dosage after conversion from PEG-Epoetin beta to darbepoetin alfa in adult hemodialysis patients: the TRANSFORM study. Adv Ther. 2014;31(11):1155-68.

29. Arrieta J, Moina I, Molina J, Gallardo I, Muñiz ML, Robledo $\mathrm{C}$, et al. Switch from epoetin to darbepoetin alfa in hemodialysis: dose equivalence and hemoglobin stability. Int J Nephrol Renovasc Dis. 2014;7:353-9.

30. Minutolo R, Borzumati M, Sposini S, Abaterusso C, Carraro G, Santoboni A, et al. Dosing penalty of erythropoiesis-stimulating agents after switching from originator to biosimilar preparations in stable hemodialysis patients. Am J Kidney Dis. 2016;68(1):170-2.
31. Minutolo R, Bolasco P, Chiodini P, Sposini S, Borzumati M, Abaterusso $\mathrm{C}$, et al. Effectiveness of switch to erythropoiesisstimulating agent (ESA) biosimilars versus maintenance of ESA originators in the real-life setting: matched-control study in hemodialysis patients. Clin Drug Investig. 2017;37(10):965-73.

32. Inotai A, Prins CPJ, Csanádi M, Vitezic D, Codreanu C, Kaló $\mathrm{Z}$. Is there a reason for concern or is it just hype? A systematic literature review of the clinical consequences of switching from originator biologics to biosimilars. Expert Opin Biol Ther. 2017;17(8):915-26.

33. Food and Drug Administration. Scientific considerations in demonstrating biosimilarity to a reference product: guidance for industry. Silver Spring: Food and Drug Administration; 2015. https ://www.fda.gov/downloads/drugs/guidances/ucm291128.pdf. Accessed 15 Apr 2017.

34. Biosimilar medicines. Positioning statements on physician-led switching for biosimilar medicines. https://www.medicinesforeur ope.com/wp-content/uploads/2017/03/M-Biosimilars-Overviewof-positions-on-physician-led-switching.pdf. Accessed 25 May 2019.

35. Kurki P, van Aerts L, Wolff-Holz E, Giezen T, Skibeli V, Weise M. Interchangeability: a European perspective. BioDrugs. 2017;31(2):83-91.

36. Barlas S. FDA Guidance on biosimilar interchangeability elicits diverse views: current and potential marketers complain about too-high hurdles. P\&T. 2017;42(8):509-12.

37. Aronson JK, Goldacre B, Ferner RE. Prescribing biosimilars. BMJ. 2018;362:k3141.

\section{Affiliations}

\section{Valeria Belleudi ${ }^{1}$ - Francesco Trotta $^{2} \cdot$ Antonio Addis $^{1} \cdot$ Ylenia Ingrasciotta ${ }^{3} \cdot$ Valentina lentile $^{4} \cdot$ Michele Tari $^{5}$. Rosa Gini ${ }^{6}$. Maurizio Pastorello ${ }^{7}$. Salvatore Scondotto ${ }^{8}$. Pasquale Cananzi ${ }^{9}$. Giuseppe Traversa ${ }^{10}$. Marina Davoli ${ }^{1}$. Gianluca Trifirò ${ }^{3,4}$ on behalf of the Italian Biosimilar Network (ItaBioNet)}

1 Department of Epidemiology, Lazio Regional Health Service, Via Cristoforo Colombo, 112, 00147 Rome, Italy

2 Italian Medicines Agency, Rome, Italy

3 Department of Biomedical and Dental Sciences and Morphofunctional Imaging, University of Messina, Messina, Italy

4 Unit of Clinical Pharmacology, A.O.U. Policlinico "G. Martino", Messina, Italy

5 Caserta-1 Local Health Service, Caserta, Italy

6 Toscana Regional Healthcare Agency, Florence, Italy
7 Department of Pharmacy, Palermo Local Health Unit, Palermo, Italy

8 Department of Epidemiologic Observatory, Health Department of Sicily, Palermo, Italy

9 Sicilian Regional Centre of Pharmacovigilance, Servizio 7-Farmaceutica, Health Department of Sicily, Palermo, Italy

10 Pharmacoepidemiology Unit, National Centre for Epidemiology, Italian National Institute of Health, Rome, Italy 